\title{
The Many Perceptions of Reality in Search of the Self: Reading Yangsze Choo's The Ghost Bride
}

\author{
Sanghamitra Dalal \\ Universiti Teknologi MARA, Selangor, Malaysia
}

\begin{abstract}
:
In this article I will read Yangsze Choo's speculative fiction novel The Ghost Bride (2013), which not only refers to the ancient Chinese tradition of "ghost-marriage" or "spirit-weddings" but also traverses the phantasmic world of the Chinese afterlife and an imaginary land conceived as the "Plains of the Dead". I will examine how Choo effectively utilizes Chinese myths and folklore in order to construct the parallel worlds of the living and the dead. I will particularly focus on the fictional character, the mysterious guardian spirit, Er Lang, who evokes the myth of Er Lang Shen, the great Chinese warrior God of Heaven who possesses an esoteric Third-Eye of Enlightenment on his forehead. In the course of my analysis, I will explore the problematics of the concept of reality in relation to the genre of speculative fiction, which stereotypically embodies elements of fantasy. However, I will argue, through my reading of The Ghost Bride, that human perceptions of reality should not be constrained by what can only be seen with mortal eyes, but what can also be discerned through the eyes of the inner mind.
\end{abstract}

Keywords: Speculative Fiction, Chinese mythology, folklore, Third Eye, alternate realities

\section{Introduction}

In this article I will read the fourth-generation Chinese-Malaysian diasporic author Yangsze Choo's speculative fiction The Ghost Bride (2013) as a novel that not only references the ancient Chinese tradition of "ghost-marriage" or "spirit-weddings" but also traverses the phantasmic world of the Chinese afterlife and an imaginary land conceived as the "Plains of the Dead". In the course of my reading, I will explore how Choo deftly utilizes Chinese mythology and folk beliefs in order to evoke a parallel universe in her novel; however, my particular focus will be on the fictional character, the mysterious guardian spirit Er Lang, whose perennial presence in both the mortal and the spirit worlds of the novel is significantly instrumental in assisting the young female protagonist, Li Lan, to envisage an unusual future for herself - in quest of an illusory happiness. As the fictional name Er Lang is reminiscent of Er Lang Shen, the great Chinese warrior God of Heaven who embodies justice and righteousness and can be uniquely distinguished from the other Gods in the Chinese Pantheon through his possession of an esoteric Third-Eye of Enlightenment on his forehead, I will 
attempt to argue, through my reading of The Ghost Bride, that human perceptions of reality should not be constrained by what can only be seen with the mortal eyes, but what can also be discerned through the eyes of the inner mind.

Speculative fiction, as a comprehensive genre, encompasses a vast arena including fantasy, gothic, horror, dystopia, science fiction, post-apocalyptic fiction, ghost stories, superhero tales, alternate history, magic realism, steampunk, slipstream and many more. Even though they are commonly characterized as deviating or departing from portraying the realities of everyday life within a fictional context, Marek Oziewicz indicates that since speculative fiction cannot be defined by clear boundaries or by its resemblance to pre-constructed prototypical examples, the genre should more appropriately be signified by "a domain of activity that exists not merely through texts but through their production and reception in multiple contexts" (1). This emphasis on speculative fiction as a field of cultural production unfolds many possibilities of interpretation, "reflecting on their cultural role, especially as opposed to the work performed by mimetic, or realist narratives" (Oziewicz 1). Christopher Patterson, in Transitive Cultures: Anglophone Literatures of the Transpacific, traces the rise of speculative fiction writing in the Southeast Asian region and also examines himself as an author of speculative fiction. He is of the opinion that his use of speculative transitions in his own fictional creations acts as "a form of detachment from the trappings of the self, a means to criticize the self, to compare the self, to see outside, to refuse the gaze that demeans or steals from others" (195), which often results in "authenticating one's presence" (195), leading to a transformation of one's own self. As the selected text, The Ghost Bride, effectively extends an ancient Chinese practice of "ghost-marriage" and the folkloric beliefs of the Chinese afterlife to a paranormal world-building of the "Plains of the Dead", evoking parallel worlds, traversing across late nineteenth-century Malacca (now Melaka), the Afterworld and the Plains of the Dead, I will examine whether the inscribing of a speculative fictional realm articulates an alternative perspective of an understanding of the existing reality and whether that understanding has the possibility of transforming the young protagonist, the ghost bride in the novel.

\section{Perceptions of Reality and the Fictional World}

The etymology of the English word "reality", meaning the quality of being real, has been in use since the late fifteenth century, and can be traced back to late Latin "realis" (relating to 
things) through medieval Latin, "realitas" (often referred to in legal property matters), to French "réalité". In addition to the contemporary dictionary meaning of "reality" as "a thing that is actually experienced or seen, in contrast to what people might imagine" or "the true situations and problems that actually exist in life" (OLD), the notion of "reality" has been utilized, extended and explored in various fields of study. Parmenides, the pre-Socratic Greek philosopher of the late sixth or early fifth century BCE, who is considered the progenitor of the idea of ontology or metaphysics that led to the foundation of the major strands of Western philosophy, advocates his strict monistic beliefs on reality. His poem, "On Nature", which now only survives in fragments, outlines his account of his mystical journey to the abode of a goddess, who directs his understanding along "the path of conviction" to "apprehend true reality" (fr. 2 qtd in Palmer) which is "ungenerated and deathless, whole and uniform, and still and perfect" (fr. 8 qtd in Palmer). Palmer refers to Guthrie's interpretation of Parmenides's perception of reality as "a unity in the strictest sense, absolutely without variation or change, and thus that the world perceived by the senses is unreal" (Palmer). Parmenides's monism is eventually challenged by the proponents of pluralism, proposing the doctrine of multiplicity, through different perspectives, such as metaphysical, ontological, epistemological or logical pluralism, highlighting the fact that instead of any singularly existing reality, there are a variety of substances in nature constituting reality and there are different modes of being or different ways of knowing things.

The literary practice of depicting reality in fiction becomes even more complicated, specifically in relation to speculative fiction, as one of the predominant conventions of this particular genre is to develop a fantasy world which should inevitably involve certain realitydefying tropes usually utilized in a stereotypical fictional world-building. However, an etymological study of the word "fantasy" reveals significant connotations. The origin of "fantasy" can be traced through sources such as the Greek "phantasia", which means "imagination" or "appearance"; and also through the Greek "phantazein", which means "to make visible". Therefore, these dual implications of fantasy ironically indicate that although fantasy is illusion or imagination, it also unfolds what is invisible to the naked eye, signaling the idea that the visible reality is only partial and incomplete; and it is fantasy which is truly instrumental in illuminating what lies hidden beneath the surface of any mundane reality.

Katheryn Hume in Fantasy and Mimesis: Responses to Reality in Western Literature maintains that both fantasy and mimesis contribute to the literary representation of reality and, 
more significantly, argues that fantasies and mimetic works are "examples of some particular response to reality" (xii). According to her, among the two basic impulses that produce a literary work, one is mimesis, which is "felt as the desire to imitate, to describe, events, people, situations and objects with such verisimilitude that others can share your experience" (20); and the other is fantasy - "the desire to change givens and alter reality" (20). Her emphasis that fantasy in fiction should be considered real is particularly significant as she identifies fantasy as a deliberate departure from "consensus reality" (20), such as "food, oxygen and liquid" (xi). Nevertheless, in her opinion, fantasy is not something peripheral or which can be readily separable, but fantasies are stories "whose marvel is considered 'real', although not in the same fashion that a chair is real" (21). Therefore, Hume's argument indicates the existence of many perspectives of reality which is also corroborated by Marianne Wünsch who questions the stereotypical definitions of concepts such as "the inexplicable", "the unnatural" and "the supernatural". In Wünsch's volume (written in German) titled Die Fantastische Literatur der Frühen Moderne (1890-1930): Definition, Denkgeschichtlicher Kontext, Strukturen (1991) referred to by Laura Feldt in her The Fantastic in Religious Narrative: From Exodus to Elisha (2014), Wünsch argues that if one categorizes forms of literature by means of their relationship to "reality", one must philosophically investigate what is meant by reality itself. She perceives the concept of reality as historically variable and proposes that there is "no singular universal model of reality, only epochal reality models" (Feldt 13). Introducing the concept of "cultural knowledge" as "the total amount of true statements of an epoch" (qtd in Feldt 13), Wünsch distinguishes between reality-compatible literature (literature that does not violate the reality concept of the epoch) and non-reality-compatible literature (literature that does violate the reality concept of the epoch). However, such diverse discussions on the relationship between the idea of reality and the various fictional depictions of reality as compatible to everyday experiences, also indicate the magnitude of post-Enlightenment ideals of rationalism and empiricism which, according to Marek Oziewicz, signify the domination of the "traditional Western cultural bias in favor of literature imitating reality" (Oziewicz 1). Oziewicz's claim that the emergence of the hybrid, fluid and flexible genre of speculative fiction as a "response to the need for a blanket term for a broad range of narrative forms that subvert the postEnlightenment mindset" mainly asserts the importance of embracing "a different version of reality than the empirical-materialist one" which can be appropriately located in the quest "for the recovery of the sense of awe and wonder" (Oziewicz 1). Therefore, it is evident that 
speculative fiction not only provides the readers with an opportunity to examine the diverse perceptions of the idea of reality in general, but also - specifically in the course of analyzing The Ghost Bride, which is contextualized within a distinctive Asian/Chinese cultural backdrop - to explore whether the perceptions of reality and the self could be refashioned according to cultural beliefs and practices. In the following sections of the article, I will first explore how in the novel The Ghost Bride, Yangsze Choo and her seventeen-year-old protagonist, Pan Li Lan, travel through parallel worlds of myths, folklore, beliefs and visions. I will then examine whether the portrayals of these apparently unreal and imaginary experiences effectively articulate multiple and fluid perceptions of reality in search of the self.

\section{Li Lan's Journey through Parallel Worlds}

Yangsze Choo sets the tone of her novel immediately in the opening sentence as the narratorprotagonist, Li Lan recollects: "One evening, my father asked me whether I would like to become a ghost bride" (8). The Ghost Bride is historically contextualized in late nineteenthcentury colonial Malaya (now Malaysia), and in the town of Malacca (now Melaka) which was recognized as one of the significant port cities in the Malay Archipelago. It had attracted merchants and traders from different parts of the world including China, India, and Persia since the early sixteenth century, as it underwent successive periods of colonization by the Portuguese, Dutch and British. By 1893, when the novel is set, Malacca was a place of cultural confluence, where similarities and differences co-existed, as Li Lan points out:

But though many races - Malay, Chinese, and Indian, with a sprinkling of Arab and Jewish traders - had settled here for generations, we kept our own practices and dress. And though my father could speak Malay and some English, he still looked to China for his books and papers. Never mind that it was my grandfather who left his native soil to make his fortune trading here. (9)

However, since the family fortune has dwindled and she has only a few suitors, she is asked to marry the recently-deceased Lim Tian Ching, the son of the wealthy Lim family, an act which promises to discharge Li Lan's father of his considerable debts.

The ancient Chinese practice of the ghost-marriage or spirit-wedding was not uncommon during the nineteenth and early twentieth centuries, particularly in the Southeast Asian region, when either one or both the parties were deceased. The origins of this custom are largely unknown; Choo points out that there are a number of allusions to it in Chinese literature, 
but "its roots seem to lie in ancestor worship" (317). She also outlines some of the usual occasions for such an unusual marriage to occur, such as a living person fulfilling the wish of a dying suitor; or to elevate the rank of a mistress or a concubine to a wife who has produced an heir; or often an impoverished girl is taken into the household as a widow to perform the ancestral rites for a man who has died without any wife or descendants, which is similar to the offer received by Li Lan's father for his daughter. Choo recollects how an accidental discovery of a reference to spirit weddings while doing research among the archives of the local newspapers in Malaysia intrigued her, and she rushed off and wrote the first chapter in one sitting. The novel's context of the Chinese practice of ancestor worship and the traditional custom of ghost-marriages immediately indicates the blending of the apparent dichotomy of the real and the fantasy worlds. The Eastern mythological belief in the Afterworld and the existence of the invisible realm of the ancestors is opposed to Western philosophical discourses of reality, which are predominantly grounded in empirical evidence. In Chinese mythology, therefore, the real and the unreal, the visible and the invisible, are co-terminous and extensions of each other.

Li Lan, who lost her mother when she was a child, has been brought up by her superstitious but very caring nanny, whom she calls amah, and by her opium-addicted father, who does not at first entertain the offer of his daughter being a ghost bride for the wealthy Lim family. However, the ghost of Lim Tian Ching, Li Lan's prospective dead suitor, starts haunting her in her dreams. Thus Choo, right at the beginning of the novel, effectively blends the real world of the mortals and the illusory world of dreams and the Afterworld, where Li Lan, on one hand, is possessed by her desire for the handsome Tian Bai, the cousin of the dead Lim Tian Ching and the new heir of the Lim family; and on the other hand, is increasingly rendered distraught by the nightly hauntings by her dead suitor, who initially attempts to court her in a romantic fashion but eventually manipulates, threatens and horrifies her in his desperate bid to force her into submission: “'You don't know the extent of my influence! I'll haunt you; I'll haunt your father; I'll haunt that meddling amah of yours"' (56). A distressed Li Lan accidentally overdoses herself on the sleeping draught supplied by a medium in order to escape her daily nightmares, which eventually results in an unfortunate severance of her body and her soul. Li Lan's nightmares at the beginning of the novel indicate that her understanding of reality is circumscribed by what she hears from her amah about the Afterworld as a scary, unreal place for non-humans, which is to be feared and therefore avoided. Thus, whenever she is visited by 


\section{SARE, Vol. 57, Issue $1 \mid 2020$}

the dead Lim Tian Ching, she desperately struggles to restore her known world of reality, but eventually overdoses herself and is transported to the seemingly unreal world of the spirits and learns of a different realm of reality.

Li Lan has heard from her amah that the Chinese believe that the spirit leaves the body only when someone dies, and after the hundred days of mourning are over the spirit passes through the ten Courts of Hell for their final judgement. However, Choo conceives Li Lan's collapsed state in a different way, which is diagnosed by the doctor as follows: "She's not dead [...] She's taken an overdose that has slowed her life force drastically, yet there's still some qi circulating in her body" (87). Choo's deliberate intention of transforming Li Lan to a living ghost serves several significant purposes in the novel. Since her soul can escape the confines of the body, Li Lan can remain incognito to mortal beings and can also move around Malacca unhindered, alone and unaccompanied, which is against the customary practice for young women in the late nineteenth century. Alternatively, because of her privileged status of becoming a spirit, she can also communicate with other ghosts and mystical presences. Therefore, Li Lan undertakes the mission of unravelling the mystery of Lim Tian Ching's accidental death as he accuses his cousin, Tian Bai, of poisoning him. Her initial interest in accessing the Plains of the Dead is to stop Lim Tian Ching from appearing in her dreams; to relieve Tian Bai of the accusation of his cousin's murder; and to marry Tian Bai and live happily ever after. Such hopes and desires also manifest Li Lan's longing as shaped by the expectations of the mortal world of reality. However, her journey through the unreal Plains of the Dead generates further significance and is instrumental in her eventual transformation, indicating the limitations of what mortal eyes perceive as reality.

Yangsze Choo has altered the Chinese myth of Afterlife and created an imaginary realm which she calls the Plains of the Dead where the recently-dead ones appear in the Court of Hell before the Nine Judges, for their evaluation and judgement towards the paths of their eventual reincarnation. Choo's Plains of the Dead replicates the real Malacca in a physical sense even though time in the Plains of the Dead runs differently from the mortal world. It is in the Plains of the Dead, which is guarded by ox-headed demons and populated by ghosts of different statuses, from the puppet-servants to the privileged ones like Lim Tian Ching, that Li Lan investigates a conspiracy involving Lim Tian Ching and the corruption of one of the Nine Judges of Hell, learns her own family secrets, and meets her dead mother. Whenever she is in trouble, Er Lang, who can glide through the mortal world, the Afterworld and also the Plains 
of the Dead simultaneously, comes to her aid. The real identity of Er Lang remains shrouded in mystery in the novel. His face is always hidden under a wide-brimmed bamboo hat, and he wears distinctive, old-fashioned Han clothing: a robe, whose hem is embroidered with silver thread, tied crossover and bound by a broad sash. He wears loose trousers and boots beneath it. Li Lan recognizes that such garb is only seen in books, paintings and historical plays. However, as the name Er Lang is reminiscent of Er Lang Shen, the great Chinese warrior God of Heaven, I will now delineate the specific characteristics associated with Er Lang Shen and trace how such an evocation of a mythical allusion eventually leads young Li Lan to uncover her inner mind, in her search for truth and happiness.

\section{Er Lang Shen and the Third Eye}

Er Lang Shen, which is literally translated as "second son god", is one of the rare gods in the Chinese Pantheon with a third truth-seeking eye in the middle of his forehead. There are different versions of his origin and identity but according to legend, he is the Chinese warrior god of heaven, embodying justice and righteousness. The volume A Brief History of the Immortals of Non-Hindu Civilizations (Shri Bhagavtananda Guru) traces the roots of the myth of Er Lang Shen. According to the mythical chronicles written during the Ming dynasty of the sixteenth century, The Investiture of the Gods or The Creation of the Gods and Journey to the West, Er Lang Shen is the nephew of the Jade Emperor, assisting the Zhou army in defeating the Shang in the Battle of Muye or Mu around 1046 BCE; and he is also a deified mythical folk-legend who regulates China's torrential floods, dating variously from the Qin, Sui and Jin dynasties. A later Buddhist scripture also identified him as the second son of the Northern Heavenly King Vaishravana (Shri 106).

Er Lang Shen is usually portrayed as possessing superhuman strength, mystical abilities and superhuman durability. He can cleave an entire mountain with an axe in one stroke in order to save his mother; he can single handedly fight a multitude of demons and heavenly soldiers with his weapon, the '3-pointed-double-edged lance', which weighs 27,500 jins, equivalent to nearly 13 tons (Shri 108). He can achieve seventy-two or seventy-three types of transformations and perform various magic spells. He also possesses a unique skill known as 'Nine Turns Complex/Divine Skill' (Shri 108) which grants him superior physical durability of undefined limits, making him completely immune to any disease, poison, explosions, fire, water or even to strikes by powerful magical and mystical objects. In addition, he holds the 
power of utilizing electro-kinesis, enabling him to impart 'Heaven's punishment', by sparking devastating storms and destructive bolts of divine lightning to destroy and incinerate the evil and the wicked, an ancient skill which only the exceptionally powerful gods are able to execute (Shri 110). Even though the fictional character Er Lang in The Ghost Bride has no direct reference to Er Lang Shen, his actions in the novel, his ability to see and communicate with $\mathrm{Li}$ Lan, both in the mortal and the spirit world, particularly evident when he secretly rescues $\mathrm{Li}$ Lan from her imprisonment in the Plains of the Dead, his deathly fight against the flying beasts to help Li Lan leave the Plains of the Dead, his ability to impart his own $q i$ to Li Lan when her spirit is being depleted following her return to Malacca, and finally again his rescue of Li Lan from the dark and muddy recesses of the well where Madam Lim has thrown her, provides ample evidence of an evocation of Er Lang Shen. Choo's transforming of the mythical Er Lang Shen to the fictional Er Lang is significant, as this particular character serves as a link between the real, the fantastical, the supernatural and the mythical worlds through his ability to move between all these realms effortlessly, rendering the empirical distinction between the real and the unreal indistinct and contentious.

However, I will now particularly focus on Choo's deliberate choice of portraying Er Lang with the peculiar headgear which covers his face and evokes enigma and apprehension as Li Lan muses: "But his face was a mystery to me. Perhaps there were no features beneath his hat at all, merely a skull with loose ivory teeth or a monstrous lizard with baleful eyes" (144). According to the legend referred to in the previous paragraphs, Er Lang Shen is uniquely characterized by his third eye on his forehead which is commonly known as "The Eye of Heaven", and which is capable of distinguishing truth from lies and unraveling deceptions and disguises. The concept of the 'Third Eye', which is also known as the 'mind's eye', 'the inner eye', 'eye of the soul', 'eye of illumination' or the 'eye of wisdom' (Shumsky 14), is one of the prevalent concepts in different Eastern philosophical and spiritual traditions, predominantly signifying a mystical and esoteric notion of a speculative invisible eye, located on the middle of the forehead, providing perception beyond normal, ordinary sight or vision. The metaphorical existence of the third eye is emblematic of a gateway to the inner realms of mind and profound spaces of higher consciousness leading to a state of awakening and transcendence. In Hinduism, the third eye is the symbol of spiritual wisdom and knowledge which can be achieved through meditation, and in Buddhism, it is referred to as the eye of consciousness, unfolding the capability of experiencing the world not just with the physical 
eyes but with the internal mind (McKenna 4-5). In Taoism and in many other Chinese religious sects, the training of the third eye requires focusing attention on the area between the eyebrows with closed eyes so that it allows the body "to tune into the perfect vibration of the universe and to gain solid foundation required to reach advanced levels of meditation" (McKenna 2). In this context, McKenna introduces the idea of 'patterning' which is an ancient Taoist belief. Khoo Boo Eng in his A Simple Approach to Taoism highlights the importance of finding one's position in the natural order of things and refers to Zhi Gang Sha who states:

Tao gives rise to one; one generates two; two generates three; three generates everything. Everything originates from three; three combines with two; two combines with one; one becomes nothing. Hence, human beings will follow the pattern of earth; earth will follow the pattern of heaven; heaven is patterned by Tao and Tao follows nature (Khoo 7).

McKenna argues that since this idea of patterning is complex and intuition is required to visualize the possibilities, the third eye can assist in attaining the vision on a deeper level in order to elicit a pattern out of nature and our experiences (McKenna 6). Therefore, we can profess that Chinese mythical gods and their unique features do not solely characterize religious precepts and beliefs but can also embrace their cultural values and virtues. Although Choo's novel does not explicitly mention the existence of the third eye in the fictional character, Er Lang, I consider the allusion to the third eye of the mythic god, Er Lang Shen, is particularly significant in the course of my discussion, as the concept of the third eye can be appropriately associated with the notion of fantasy, in revealing the invisible realities, latent within the superficial realities of the mortal world. As I have already explained, the third eye, according to the Eastern philosophical beliefs, is symbolic of the inner vision, capable of looking beyond the appearances and realities. Thus, the third eye can illuminate and enlighten the human consciousness with different perceptions of reality, which the Western concept of enlightenment, based on empirical evidence and observations, fails to provide the mortal beings with.

\section{Folklore, Myth, and Perceptions of Reality}

I will now proceed to focus on the specific folklore and mythic beliefs that Choo has appropriately blended, particularly in the initial section of the novel, which is contextualized within the real location of 1893 Malacca. In the fourth chapter of The Ghost Bride, Li Lan is 
invited to the Lim mansion on the occasion of the 'Double Seventh Festival'. This particular festival, which is also known as the 'Qixi Festival' or the 'Qiqiao Festival', is observed on the seventh day of the seventh month of the Chinese lunar calendar. It celebrates the eternal love of the two heavenly lovers - the cowherd and the weaving maid. This festival is known to have been celebrated since the Han dynasty, and the earliest-known reference to this myth can be found in the oldest existing collection of Chinese poetry, namely The Classic of Poetry or Shijing or Shih-ching, dated approximately from the eleventh to seventh centuries BCE. It is a tale of love between Zhinü, the weaving maid, symbolizing the star 'Vega', lying within the constellation of Lyra, and Nulian, the cowherd, symbolizing 'Altair', within the constellation Aquila. Their love is forbidden and therefore they are banished to opposite sides of the Silver River, symbolizing the Milky Way. Only once a year, on the seventh day of the seventh month, a flock of magpies forms a bridge over the Silver River so that the lovers could unite for a day (Shri 140-141). As Li Lan hears the story from her amah she is flummoxed: "I couldn't understand why such a tragedy was considered a festival for lovers. There was no happy ending, only endless waiting on each side of a river. It seemed like a miserable way to spend eternity" (Choo 33). An elusive idea and an eventual realization of love, which is the predominant guiding force of Choo's speculative novel (as Li Lan drifts through her desperate evasion of Lim Tian Ching's paranormal offer of being a ghost bride, to her hopeless infatuation with Tian Bai, to her ultimate consciousness of her own self as she willingly surrenders herself to the extra-terrestrial Er Lang) significantly encapsulates a journey in transformation - through life and death - where the crucial decisions of real life are being consciously wielded by the apparently unreal eventualities, induced and visualized by the invisible presence of the Third Eye of Enlightenment, latent in one's own self.

Choo has effectively introduced allusions to the realms of the Afterworld even in the real world of Malacca as Li Lan, along with her amah, visits the medium, seeking help to annihilate the nightmarish visits of Lim Tian Ching to Li Lan's dreams. The medium resides near the Sam Poh Kong temple at the foot of Bukit China, which is known to be the largest Chinese cemetery outside of China, which in Li Lan's observation is "a veritable city of the dead" (63). The medium secretly instructs Li Lan to "[b]urn hell banknotes for yourself" (69); hell banknotes are the money for the dead, burnt in this world to be used in the afterlife, implying the future possibility of the convergence of the mortal life and the afterlife. As her amah arranges for the hell notes without comprehending what they are actually meant for, $\mathrm{Li}$ 
Lan's watchful eyes notice that the paper parcel containing printed stacks of hell banknotes glares with the seal of Yama, the god of hell. Yama is the mythic god of the dead and the underworld as he is originally conceptualized in the Rigveda, the ancient Indian collection of Vedic Sanskrit hymns. He has been adapted and interpreted in Buddhist philosophy as well. In the Pali Canon of Theraveda Buddhism, Yama is referred to as a king who provides judgements after death. As examined by Stephen Teiser in The Ghost Festival in Medieval China, Yama oversees the ten courts of hell and maintains the purgatorial aspects so long as evil actions on earth continue (Teiser 172-186). However, Choo utilizes this incident of Li Lan's meeting with the medium, which facilitates her interaction with the afterlife, as a gateway to Li Lan's journey towards transformation. The mysterious character of Er Lang is first introduced in the novel as Li Lan waits for the medium to finish her earlier consultation. Even though he remains a stranger during this accidental encounter, Choo effectively establishes a connection between him and Li Lan: "When the stranger finally left, he deliberately attempted to peer beneath my parasol as he passed. Amah forestalled him by lowering it so that he wouldn't catch a glimpse of my face, but he shrugged and walked on insolently, jingling the copper coins in his belt" (66). Subsequently, in the course of the novel, Choo develops an extremely unusual relationship between Li Lan and Er Lang, through their plight in the Afterworld and in the Plains of the Dead and later in Malacca, where Li Lan eventually returns, first as a spirit and then re-possessing the body left behind, but utterly transformed by all the experiences she has undergone during her phantasmagoric journey.

The relationship between Li Lan and Er Lang is distinctive not just because of their unusual interactions, which are persistently tinged with irony and sarcasm, mostly in precarious circumstances; they are exceptional as they could effectively dismantle the artificial constructions of and divisions between the real and the unreal, the natural and the supernatural. Their first glimpse of each other near the Sam Poh Kong temple is followed by their introduction in the Afterworld, where Li Lan is roaming as a living ghost, invisible to every mortal being but clearly visible to Er Lang, who calls to her when she is hiding behind one of the branches of a tree. As he seeks her assistance for his ongoing investigation of the dead Lim Tian Ching and one of the corrupt judges of hell, he also informs her that he is unable to enter the Plains of the Dead as it is a place for "human souls, a transitional place that is a shadow of the real world" (Choo 145). However, he provides her with a shining flat disk, about the size of her palm, marked with grooves from one direction to the other, narrowing down to a sharp 
edge at one end. Assuring her that there are other areas and opportunities where he might be of help, he directs her on its usage: "You must hold it up and blow upon the rippled edge. Then call my name and, if I can, I will come to you" (Choo 145). Er Lang keeps his promise. Therefore, being ably guided by Er Lang, whose supernatural abilities empower him to move between the mortal world, the Afterworld and the Plains of the Dead, Li Lan's experiences and consciousness are extended beyond the mortal world of realities. She not only partakes in the exceptional journey between the realms of the mortal and the immortal, but is also transformed by the inner enlightenment the experience yields: "I had experienced a hidden realm, which though terrifying, has also been a source of pure wonder [...] I was no longer the same girl" (Choo 290).

Li Lan, who at the beginning of the novel, appears as a demure maiden under the overwhelming protection of her amah, eventually evolves to a strong, determined voice, who is capable of becoming the architect of her own destiny. Her traversing through different realms of reality has developed in her a profound wisdom and illumination regarding the complexity of human consciousness and the simultaneous layers of reality, which could be seen by mortal eyes and which could also be experienced within one's inner mind. She is no longer blindly infatuated by Tian Bai and is unconstrained by societal expectations. Therefore, I contend that the final paragraph of the novel, which highlights Li Lan's emancipated, albeit unusual, choice in search of an idea of an illusory happiness, embodies not only her transformation but also highlights the multiple realities of myths, folklore, personal perceptions and cultural beliefs. Although being completely aware of the predictability of the interactions between the spirits and the humans remaining "tantalizingly unresolved" (Choo 298), as it has been chronicled in the tales from China, Li Lan decides to sculpt her own reality, prompted by her inner illumination:

But I want to see Er Lang. I don't want to wait fifty years, or cheat Tian Bai out of a love that he will never have. In the darkness of a thousand withered souls, it was Er Lang's hand that I sought, and his voice that I longed to hear. Perhaps it is selfish of me, but an uncertain future with him, in all its laughter and quarrels, is better than being left behind. Though given how much I resisted becoming Lim Tian Ching's ghost wife, it's not even funny that I'm willing to leave my family for a man who isn't human. When Er Lang comes for his answer, I will tell him that I've always thought he was a monster. And that I want to be his bride. (Choo 316) 
However, Yangsze Choo has located Li Lan's propensity for transformation much earlier in the novel, within a significant Taoist myth, as she referred to the renowned Chinese philosopher, Zhuangzi, who lived around the fourth century BCE. Li Lan recalls copying a passage from the famous butterfly dream which is attributed to Zhuangzi. As he wakes up from his dream, Zhuangzi claims that "he didn't know whether he was a man who dreamed he was a butterfly or a butterfly who dreamed he was a man" (Choo 64). This well-known parable signifies the theme of transformation and symbolizes the complex dichotomy between waking and dreaming, which relates to the contentious relationship between reality and illusion.

Yangsze Choo's speculative work The Ghost Bride thus reflects a dichotomy throughout the novel, as she constantly constructs the parallel worlds of the living and the dead, and often in the course of blending the two, highlights the dubious distinction between appearance and reality. She asserts that she has always been interested in what she terms as mirror worlds: "I've always been interested in the idea of parallel or mirror worlds, and the human capacity for holding contradictory beliefs. The question is what reality you see, and how it affects your understanding of the world, is always in flux" (Matthewson). In another interview, Choo extends her understanding of the mirror world and her perception of reality as she suggests: "[...] there's a world that is seen, and a world that is not [...] And perhaps in the end, reality is what you end up believing in. Two people can see the same event and will recall it significantly differently" (McHugh). Moreover, she further alludes to the Taoist philosophy identifying the importance of patterning that I referred to in the earlier section. Choo claims: "The interesting thing about people is that we're always searching for patterns. And maybe that's something that we're built to do. When there is no pattern, it feels very unsatisfying. We're always looking for something, and it may or may not be true, but your mind finds pattern in what you see" (McHugh). In the course of my reading of The Ghost Bride, I have sought to trace how folklore and mythical beliefs of certain cultural traditions are able to construct parallel worlds of reality, which exhibit similar patterns of reckoning. I have also focused on the importance of the esoteric and philosophical concept of the Third Eye of Enlightenment in unraveling the inner mind of consciousness. As the young Li Lan of the mortal world promises to undertake the enigmatic journey of togetherness with the ageless, mysterious spirit of $\mathrm{Er}$ Lang in the Afterworld, her inexplicable decision, made in her search for happiness, appropriately signifies that human perceptions of reality are capable of transcending the singular and fixed notion of consensus reality, representing the physical, external world. 
Consequently, the personification of Er Lang in Yangsze Choo's The Ghost Bride effectively articulates the endless possibilities of perceiving alternate realities - not only by what can be seen with the mortal eyes, but what can also be discerned through the eyes of the inner mind.

\section{Works Cited}

Choo, Yangsze. The Ghost Bride. HarperCollins ebook, 2013.

Feldt, Laura. The Fantastic in Religious Narrative from Exodus to Elisha. Routledge, 2014.

Hume, Kathryn. Fantasy and Mimesis: Responses to Reality in Western Literature. 1984. Routledge Revivals, Routledge, 2014.

Khoo Boo Eng. A Simple Approach to Taoism: Of Gods and Deities. Partridge Publishing, 2014.

Matthewson, Amy. "Interview with Yangsze Choo, Author of The Ghost Bride". 2019. https://chinesebooksforyoungreaders.wordpress.com/2019/05/14/interview-withyangsze-choo-author-of-the-ghost-bride/.

McHugh, Kerry. "Yangsze Choo: A Melting Pot of Superstitions". 2018. https://www.shelfawareness.com $/$ max-issue.html?issue $=308 \# \mathrm{~m} 653$.

McKenna, Alex. Third Eye: Mind Power, Intuition and Psychic Awareness. $2^{\text {nd }}$ edn. Lulu.com, 2015.

Oxford Learner's Dictionary (OLD).

www.oxfordlearnersdictionaries.com/definition/english/reality.

Oziewicz, Marek. Speculative Fiction. Oxford Research Encyclopedia of Literature. 2017. DOI: 10.1093/acrefore/9780190201098.013.78.

Palmer, John. "Parmenides". D. Clayman edited Oxford Bibliographies in Classics. Oxford University Press, 2013. DOI: 10.1093/OBO/ 9780195389661-0156.

Patterson, Christopher B. Transitive Cultures: Anglophone Literatures of the Transpacific. Rutgers University Press, 2018.

Shri Bhagavtananda Guru. A Brief History of the Immortals of Non-Hindu Civilizations. Notion Press, 2015.

Shumsky, Susan. Awaken Your Third Eye: How Accessing Your Sixth Sense Can Help You Find Knowledge, Illumination and Intuition. The Career Press, 2015. 
SARE, Vol. 57, Issue 1| 2020

Teiser, Stephen F. The Ghost Festival in Medieval China. Princeton University Press, 1996. 